\title{
The Roles of Digital Exhibition in Enhancing Immersive Experience and Purchase Intention
}

\author{
Sojung Yoon \\ Yonsei University \\ yoon3110@yonsei.ac.kr
}

\author{
Jai-Yeol Son \\ Yonsei University \\ json@yonsei.ac.kr
}

\begin{abstract}
Museums in modern society serve to a broader public than their early predecessors. In response to such transition, many art museums now open digital exhibitions to provide immersive experience and maximize user interaction. This paper focuses on two such features - animated image and storytelling description - and their effect on museum visitors' immersive experience and willingness-to-pay price premium (WTP). Our results indicate that animated images and storytelling description not only enhance immersion and WTP but also are more effective when adopted together. This paper contributes to both IS literature and museum industry by providing comprehensive understandings of how digital exhibition features enhance museum visitors immersive experience and purchase intention.
\end{abstract}

\section{Introduction}

As institutions which collect, preserve and present artworks, art museums have functioned as a source of public education for a long period of time. Despite their long history, however, art museums now face a major change in their market. That is, museums in modern society serve to a broader public than their early predecessors [1]. This transition from elitism to inclusion is crucial because it transforms art museums into tourism sites and their visitors into consumers; various marketing strategies and new exhibition technologies are thus required [2].

In response to such transition, many art museums have incorporated diverse information technologies, such as audio guides, interactive kiosks and animated videos, to attract and appeal to more people [3]. One of the key objectives of using diverse technologies is the curation of immersive experiences [4]. Indeed, a number of art museums have started to open digital exhibitions to provide immersive experience and maximize user interaction. For instance, in 2019, Atelier Des Lumières, a digital art museum in France, attracted more than 1.2 million visitors to its 30-minute immersive exhibition of Gustav Klimt's paintings [5]. Moreover, in 2020, Bunker de Lumières, a digital exhibition located in Jeju Island, South Korea, attracted more than 100,000 visitors in just 47 days [6].

Despite the growing popularity of digital exhibitions, conflicting perspectives towards digitalization of artworks still remain. For instance, researchers have demonstrated that digital exhibition has an advantage of emphasizing the experiential value by expanding visitors' sense of immediacy and participation, which eventually lead to increase in revenue [7]. Technology-based exhibitions could reenergize the relationship between art museums and their visitors [3]. On contrary, skeptics of digital exhibitions are concerned of losing physicality and static nature of art objects, straying from art museums' original missions to preserve and educate, and subsidizing the cost of technological initiatives. [8, 9, 10].

The transition from traditional to digital exhibitions has drawn considerable attention from researchers of diverse fields, including Information Systems (IS), as well. After demonstrating key advantages of digitalizing art collections, researchers have examined factors that maximize visitors' satisfaction in digital exhibitions [11]. For instance, both system attributes (i.e., media richness) as well as visitor attributes (i.e., personal innovativeness and computer self-efficacy) are found to increase visitors' level of engagement in digital exhibitions [12]. Moreover, the use of multiple digital technologies, rather than a single digital feature, could contribute to creation of values for both museums and visitors [13]. Most importantly, a number of researchers have revealed that the role of digital exhibitions extends from enhancing visitors' satisfaction to increasing their purchase intentions [14].

While several researchers have conducted case studies to assess museum institutions' affordance of digital technologies, little is known about the 
relationship between the specific features of digital exhibition and visitors' sense of immersion, and how such relationship affects visitors' purchase intentions [4]. Furthermore, while museums have recently been under substantial digital transformation, there is a lack of IS research in this context. Therefore, we aim to provide a comprehensive understanding of both immersive experience and economic values of digital exhibition by addressing the following research questions:

(1) RQ1: How do animated images and storytelling descriptions affect visitors' immersive experience?

(2) RQ2: How does immersive experience affect visitors' willingness-to-pay price premium $(W T P)$ ?

The findings of this paper contribute to both IS literature and museum industry. While there have been active IS researches in tourism, museum industry has received little attention despite its substantial market size of 12 billion dollars a year in the United States [15]. The newly introduced immersive technologies in today's art museums have brought various research opportunities for IS researchers [4]. To the best of our knowledge, this paper is one of the first to specify distinct features of digital exhibition and assess the impact of each feature on museum visitors' immersive experience and purchase intention. This paper thus contributes to the IS literature by providing comprehensive understanding of art museums' adoption of digital technologies. Moreover, by assessing the economic value of novel technologies, this paper provides managerial insights of transforming traditional exhibitions into digital exhibitions. Lastly, as museums are central segments of cultural industry, this paper promotes future IS researchers to expand their research area to a broader interdisciplinary field.

\section{Theoretical background and research hypotheses}

\subsection{Digital exhibition}

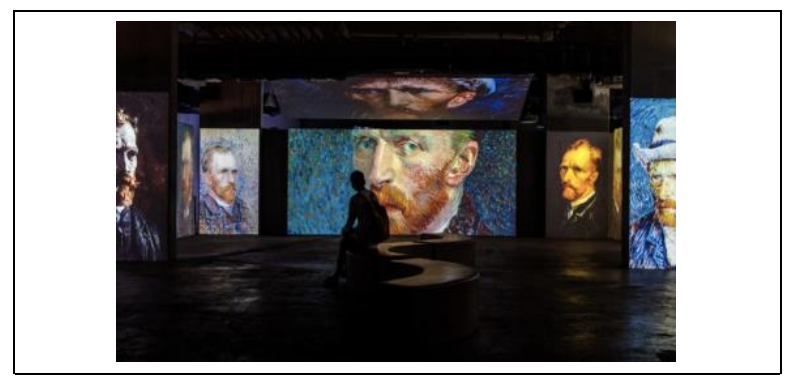

Figure 1. Digital exhibition
Digital exhibition is an exhibition that "assembles, interlinks and disseminates digital multimedia objects" to maximize user interaction [16]. Instead of presenting brick-and-mortar artworks, digital exhibition relocates traditional artworks into a digital screen. For instance, in digital exhibitions, a person in a painting may disappear from the frame, dance to the music, or even interact with visitors, offering them a sense of immersion. Figure 1 demonstrates an example of a digital exhibition [17].

2.1.1. Immersion. One of the primary purposes of digital exhibitions is to increase visitors' sense of immersion. In general, immersion is defined as "a psychological state characterized by perceiving oneself to be enveloped by [...] an environment that provides a continuous stream of stimuli and experiences" [18]. Agarwal and Karahanna [19] have further explained immersion as the state of complete engagement with all of attention focused on a certain task. In the context of art museum, researchers agree upon the consensus that immersion is a comprehensive and realistic experience that dominates attention and perceptual apparatus $[20,21]$. It is important to note that immersive experience is not limited to a visual sense. In fact, many museums attempt create a multi-sensory exhibition to establish immersive experiences [22]. Specifically, this paper follows $\mathrm{He}$ et al. [23]'s classification of immersion into experiential value and imagery vividness.

As a relativistic sense of visitors' interaction with artistic objects, experiential value is a subjective appreciation of the artistic experience in a museum [23]. In the context of this paper, experiential value indicates how museum visitors enjoy their experience with the visualization of the artworks. Experiential value is a crucial factor in understanding consumer behavior in tourism industry, as most of the products in tourism industry, including art exhibitions, are experience goods [24]. As consumers of experience goods evaluate their purchases based on the benefits received for the price paid, perceived experiential value is key to the success or failure of museum business [25]. Thus, in this paper, experiential value is measured as the key index of museum visitors' feeling of immersion.

The second aspect of immersion in art museums is imagery vividness. Imagery vividness involves the clarity with which one experiences an image. It is different from visual vividness in that it involves not only visual image but also mental image of one's experiences [26]. The mental imagery helps visitors to fully understand artists' intentions and perspectives by combining sensory input with emotional perception and redefining how visitors themselves feel about the 
artworks [27]. Imagery vividness is therefore a decisive factor in assessing visitors' satisfaction in their museum experience because of its strong influence on the ratings of aesthetic values [28]. In managerial perspective, imagery vividness is one of the factors that directly affect brand loyalty and future consumption [29]. Therefore, in this paper, imagery vividness is examined to determine the level of immersion from the digital exhibition experience.

2.1.2. Animation. Digital exhibitions possess distinctive features that are not available in traditional exhibitions. This paper focuses on two of such features: animated image and storytelling description. Animation is a common digitalization practice that combines temporal sense and visual images [30]. That is, compared to traditional still images, animated images in digital exhibitions require certain period of time to fully endorse the artworks [31]. For instance, in Atelier des Lumières, visitors were asked to watch the entire sequence of Gustav Klimt's animated paintings for 30 minutes [5]. Such inclusion of temporality into the artworks is quite similar to the experiences that people encounter in reality, where countless actions and sounds take place over the course of time. Digital artworks that integrate both temporal and visual senses thus add liveliness and vigor to the museum experience. Hypothesis 1: Animated image is positively related to museum visitors' experiential values.

Hypothesis 2: Animated image is positively related to museum visitors' imagery vividness.

2.1.3. Storytelling. In traditional art museums, museum labels - twenty to fifty-word descriptions about the exhibited artworks - provide textual commentary of the artworks. However, the multisensory digital exhibitions offer much more than informative descriptions; they present stories. As a narrative that conveys culture, history and values, storytelling is a powerful method to unite people and ideas [32]. Storytelling is consisted of 'story', a pattern of information from which the brain is able to find meanings, and 'telling', an act of conveying information to the audience [33]. In digital exhibitions, people and objects in the paintings act, interact, and even speak in intriguing ways to convey meaningful messages to the audience. Storytelling in digital exhibitions thus involves an interaction between the teller (i.e., artworks) and the listener (i.e., visitors). It is inherently participatory and immersive, as the teller of the story invites listeners into diverse situations from which the listeners coulld emotionally relate. Thus, Hypothesis 3: Storytelling description is positively related to museum visitors' experiential values.

Hypothesis 4: Storytelling description is positively related to museum visitors' imagery vividness.

2.1.4. The interaction effects of animation and storytelling. Previous studies of digital exhibition emphasize that the use of multiple technologies add values to both museums and visitors [13]. Specifically, the combination of visual and aural senses is found to "offer an interesting context of interface design and cognitive psychology exploration" [34]. As such, in addition to the main effect of each features, we examine the interaction effect of these features on museum visitors' immersive experiences.

Hypothesis 5: The effect of animated image on experiential values is higher with storytelling description than with informative description.

Hypothesis 6: The effect of animated image on imagery vividness is higher with storytelling description than with informative description.

\subsection{Willingness-to-pay price premium}

In addition to the main and interactive effects of digital exhibition features on visitors' immersive experience, this paper further examines how such immersion impacts visitors' willingness-to-pay price premium (WTP). Traditional economic literatures outline price premium as the price that yields aboveaverage profits [35]. In the same vein, WTP of this paper is defined as visitors' willingness to pay at a higher price than the normal or competitor's price [23]. When making an experiential purchase (e.g., exhibition ticket), consumers tend to value the opportunity to enhance their enjoyment of experience [36]. That is, consumers of experiential goods, compared to those of material goods, are more likely to pay price premiums as long as their experience could increase their satisfaction and well-being [37]. Therefore, we expect that the immersive experiences from digital exhibitions would have positive impact on WTP:

Hypothesis 7: Experiential value positively affects museum visitors' WTP.

Hypothesis 8: Imagery vividness positively affects museum visitors' WTP.

The research framework of this paper is illustrated in Figure 2. 


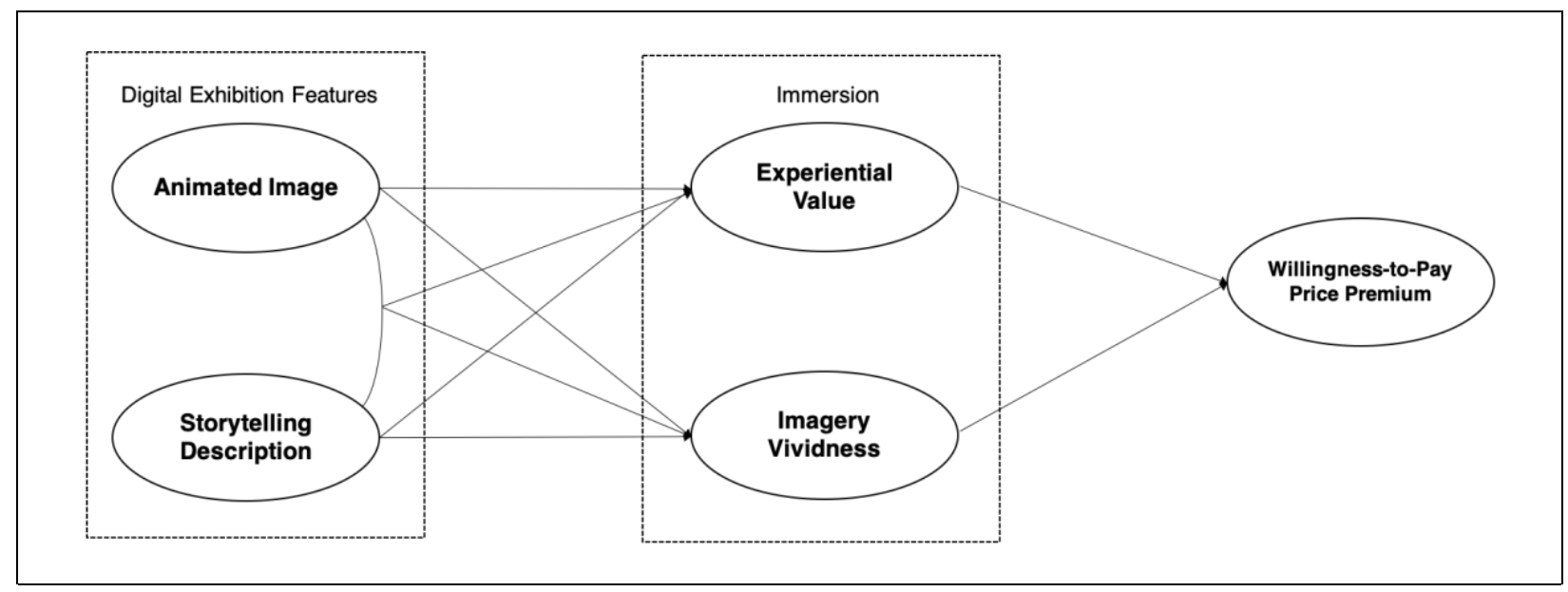

Figure 2. Research framework

Table 1. Different combinations of artworks

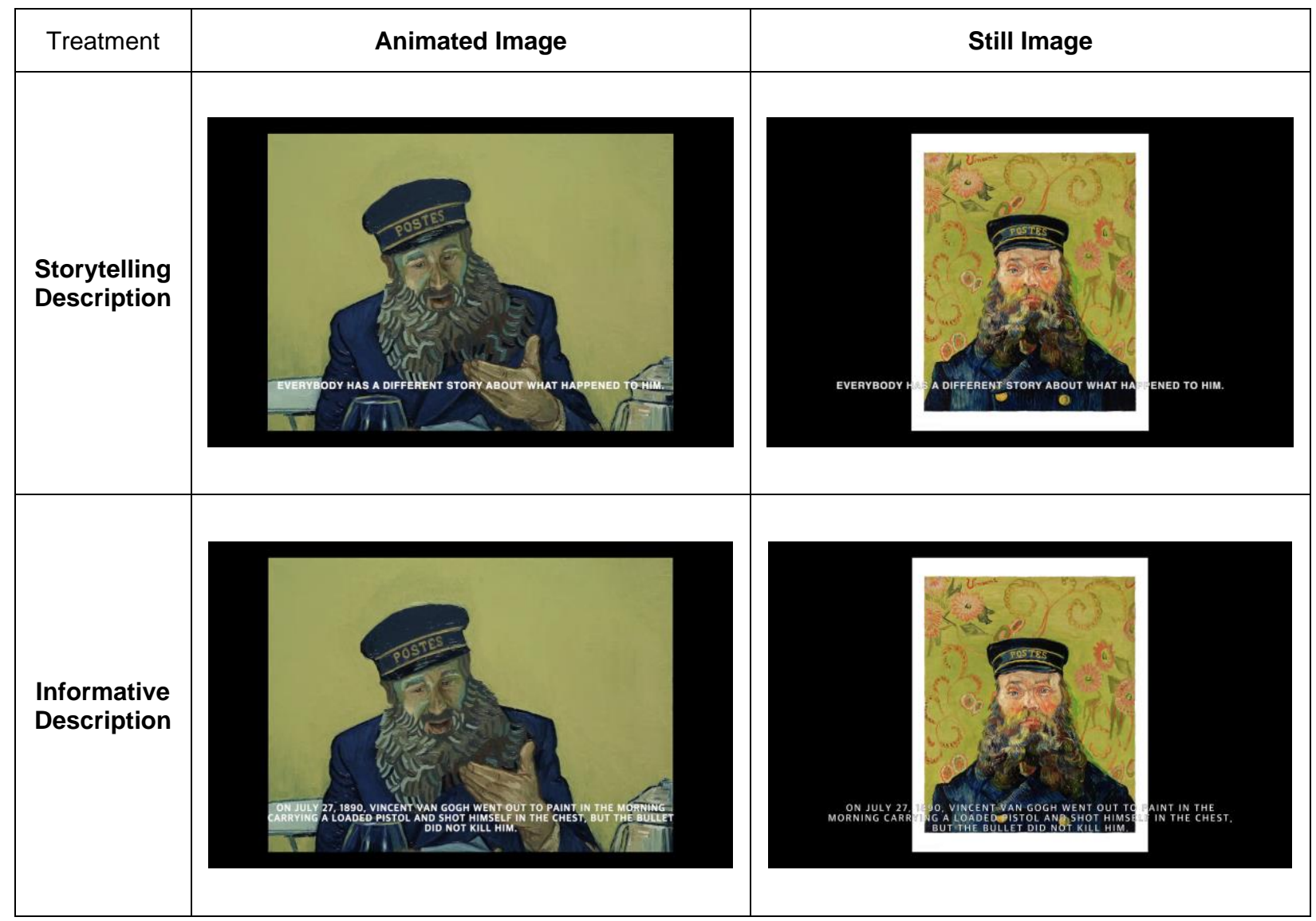

\section{Research methodology}

\subsection{Experiment setting}

To test the proposed hypotheses, a two (art types: still image versus animated image) by two (description types: informative description versus storytelling description) experimental design was employed. The four artworks, each of which contains unique combination of art types and description types, are employed to measure the effect of animated image and storytelling description. As for the animated image, participants were presented with a trailer video of Loving Vincent (2017), a world's first fully painted animation film with 64,000 frames in oil paintings in 
the style identical to that of Vincent van Gogh [38]. The trailer of Loving Vincent is selected as the treatment of animated image because the movement of characters in the film is identical to that of objects in digital exhibitions. The trailer is played for approximately one-minute and presents six paintings of Vincent van Gogh in animated format. As for the treatment of the still images, the same six paintings are presented but in a traditional, still format. These paintings include: Landscape with Chariot (1890), Portrait of Adeline Ravoux (1890), Portrait of Postman Roulin (1888), Bedroom in Arles (1888), Café Terrace at Night (1888), and Self Portrait (1889).

The description type is manipulated by the conveyance of either informative description or storytelling description. Both descriptions provide brief introduction about Van Gogh's commitment of suicide and numerous speculations regarding his death. However, while the storytelling description contains the voices of actors and actresses in Loving Vincent, the informative description consists of a voice narration about autobiographic description. Detailed information and screenshots of each treatment are provided in Table 1.

\subsection{Experiment procedures}

Before conducting the main experiment, a pilot test with a sample 20 undergraduate students was conducted to collect small-scale data and receive feedback on the scale items. The main study was initiated after confirming the satisfactory results. The participants of the main experiment were 120 undergraduate students (who did not participate in the pilot test) from a major university in South Korea. The experiment took place online and participants were provided with links accessible via PC and mobile environment. In the beginning of the experiment, participants were instructed with a scenario of visiting two different types of art exhibitions. In the first exhibition, all participants were exposed to the traditional, plain paintings of Vincent van Gogh. Then, they were randomly assigned into one of the four digital exhibitions that displayed the same paintings but in different combination of art types and description types (see Table 1). After watching the two art exhibitions for approximately 2 minutes, participants were instructed to complete the postexperiment questionnaire that measured immersive experience and WTP. The questionnaire also measured demographic information and control variables as well. On average, participants have spent approximately 5 to 8 minutes to complete the experiment and were rewarded with a coffee coupon that is worth US \$5.

\subsection{Measurement}

Measurement items for experiential value were adapted from the measurement scales of Mathwick et al. [39]. However, as the current study is concerned with museum visitors' experiences rather than the shopping preferences in retail systems, the items were adapted to focus on the effectiveness of artworks in creating satisfactory values. The imagery vividness was measured with five items developed by Bone and Ellen [26]. Instead of imagery vividness towards brands, the keywords were adjusted to measure participants' imagery vividness towards exhibited artworks. In particular, five aspects of imagery vividness - clarity, vividness, intensity, liveliness, and definition - were measured. The three items for WTP, which asked for the willingness to pay higher ticket price than traditional exhibition, were adapted from Baker and Crompton [40] and Dwivedi et al. [41]. All items were measured on a 7-point Likert scale with 1 meaning "not at all likely" and 7 meaning "extremely likely". Furthermore, participants' previous visits to art exhibitions were further measured as a control covariate that might affect individuals' behavioural responses to the exhibited artworks. As the experiment was conducted in South Korea, the questionnaire was translated into Korean first, and then a backward translation was conducted.

\section{Data analysis}

\subsection{Participants background information}

Participants were invited and surveyed online for five days from May 18 to May 22, 2020. The participants were undergraduate students from a management course. After the experiment, in order to screen out unsuitable respondents, participants were asked whether they have received story-like descriptions or factual descriptions, depending on the experiment group they were assigned to. Only those who answered correctly to the intended treatment were ultimately measured. After dropping 9 participants who did not pass the manipulation check, a total of 111 participants were included in the analysis. Among the final participants, $38.74 \%$ were female and $61.26 \%$ male. The age ranged from 20 to 28 , with the average age of 23. The monthly income ranged from $\$ 0$ to $\$ 3,000$ or higher. On the question about the number of visits to art exhibitions in a year, approximately $40 \%$ answered that they have visited at least 3 art exhibitions. Detailed demographic information is outlined in Table 2. 
Table 2. Demographic information

\begin{tabular}{|c|c|c|c|}
\hline \multicolumn{2}{|c|}{ Demographic variable } & Frequency & Percentage \\
\hline \multirow{2}{*}{ Gender } & Female & 43 & 38.74 \\
\hline & Male & 68 & 61.26 \\
\hline \multirow{3}{*}{ Age (year) } & $20-22$ & 54 & 48.65 \\
\hline & 23-25 & 47 & 42.34 \\
\hline & $26-28$ & 10 & 9.01 \\
\hline \multirow{4}{*}{$\begin{array}{l}\text { Monthly } \\
\text { income } \\
\text { (US\$) }\end{array}$} & $0-1,000$ & 92 & 82.88 \\
\hline & $1,001-2,000$ & 13 & 11.71 \\
\hline & $2,001-3,000$ & 2 & 1.80 \\
\hline & Over 3,001 & 4 & 3.61 \\
\hline \multirow{4}{*}{$\begin{array}{l}\text { Prior } \\
\text { museum } \\
\text { experiences } \\
\text { (number of } \\
\text { visits) }\end{array}$} & $0-2$ & 67 & 60.36 \\
\hline & $3-5$ & 26 & 23.42 \\
\hline & $6-8$ & 13 & 11.71 \\
\hline & Over 9 & 5 & 0.45 \\
\hline
\end{tabular}

\subsection{Experiential value}

Following Yi et al. [42], the multivariate analysis of variance (MANOVA) was first conducted on both experiential value and imagery vividness. Gender, age, income, and prior museum experiences were included as covariates. The Cronbach's alphas for experiential value and imagery vividness are 0.918 and 0.936, respectively, indicating adequate internal consistency of the measurement (i.e., above 0.70) [43]. The results demonstrate that there is a significant interaction effect between animated image and storytelling descriptions on both experiential value $(p<0.001)$ and imagery vividness $(p<0.05)$. Afterwards, follow-up ANOVAs were conducted to examine the effects of animated image and storytelling description on each of the two dependent variables separately.

ANOVA results on the experiential value reveal the significant main effect of animated images $(\mathrm{F}(1,103)=$ $3.542, p<0.1$ ), indicating that the animated images, compared to still images, led to a significantly higher level of experiential value. Therefore, the $\mathrm{H} 1$ was supported. Furthermore, the storytelling description of the artworks also had a significant positive effect $(\mathrm{F}(1,103)=16.675, p<0.001)$. The results thus reveal that presenting storytelling descriptions also resulted in significantly higher level of experiential value than presenting informative descriptions, thus supporting $\mathrm{H} 2$. Lastly, there was a significant interaction effect between animated images and storytelling descriptions on experiential value $(\mathrm{F}(1,113)=20.488, p<0.001$; see Tables 3 and 4). As a result, H5 was supported as well.

Table 3. ANOVA test - main and interaction effects

\begin{tabular}{|c|c|c|c|c|c|}
\hline Source & $\begin{array}{c}\text { Dependent } \\
\text { variable }\end{array}$ & df & $\begin{array}{l}\text { Mean } \\
\text { square }\end{array}$ & $\mathbf{F}$ & Sig. \\
\hline \multirow{2}{*}{$\begin{array}{l}\text { Animated } \\
\text { image }\end{array}$} & $\begin{array}{l}\text { Experiential } \\
\text { value }\end{array}$ & 1 & 4.884 & 3.542 & 0.063 \\
\hline & $\begin{array}{l}\text { Imagery } \\
\text { vividness }\end{array}$ & 1 & 0.002 & 0.001 & 0.974 \\
\hline \multirow{2}{*}{$\begin{array}{l}\text { Storytelling } \\
\text { description }\end{array}$} & $\begin{array}{l}\text { Experiential } \\
\text { value }\end{array}$ & 1 & 22.989 & 16.675 & 0.000 \\
\hline & $\begin{array}{l}\text { Imagery } \\
\text { vividness }\end{array}$ & 1 & 17.337 & 8.614 & 0.004 \\
\hline \multirow{2}{*}{$\begin{array}{l}\text { Animated } \\
\text { image } \times \\
\text { Storytelling } \\
\text { description }\end{array}$} & $\begin{array}{l}\text { Experiential } \\
\text { value }\end{array}$ & 1 & 28.246 & 20.488 & 0.000 \\
\hline & $\begin{array}{l}\text { Imagery } \\
\text { vividness }\end{array}$ & 1 & 10.704 & 5.318 & 0.023 \\
\hline
\end{tabular}

Table 4. Means and standard deviations of the four conditions

\begin{tabular}{|l|l|c|c|}
\hline \multicolumn{2}{|c|}{} & $\begin{array}{c}\text { Animated } \\
\text { image }\end{array}$ & Still image \\
\hline \multirow{4}{*}{$\begin{array}{l}\text { Experiential } \\
\text { value }\end{array}$} & $\begin{array}{l}\text { Storytelling } \\
\text { description }\end{array}$ & $\begin{array}{c}5.717 \\
(0.179)\end{array}$ & $\begin{array}{c}5.042 \\
(0.239)\end{array}$ \\
\cline { 2 - 5 } & $\begin{array}{c}\text { Informative } \\
\text { description }\end{array}$ & $\begin{array}{c}3.631 \\
(0.295)\end{array}$ & $\begin{array}{c}4.976 \\
(0.207)\end{array}$ \\
\hline \multirow{4}{*}{$\begin{array}{l}\text { Imagery } \\
\text { vividness }\end{array}$} & Storytelling & 4.911 & 4.3 \\
& description & $(0.231)$ & $(0.251)$ \\
\cline { 2 - 5 } & Informative & 3.592 & 4.152 \\
& description & $(0.358)$ & $(0.237)$ \\
\hline
\end{tabular}




\subsection{Imagery vividness}

ANOVA result of animated images on participants' imagery vividness demonstrates that the presence of animated images did not have a significant main effect $(\mathrm{F}(1,103)=0.001, p>0.1)$, indicating that participants did not experience significant level of imagery vividness when they were presented with animated images. Therefore, H3 was not supported. Storytelling description, on the other hand, had a significant and positive effect on the imagery vividness, thus supporting $\mathrm{H} 4 \quad(\mathrm{~F}(1,103)=8.614, \quad p<0.01)$. Interestingly, there was a significant interaction effect between animated images and storytelling description on imagery vividness, supporting $\mathrm{H} 6(\mathrm{~F}(1,103)=$ 5.318, $p<0.05$; see Tables 3 and 4). The interaction effect of animated images and storytelling descriptions on both experiential value and imagery vividness indicates that animated images have greater impact on participants' experiential value and imagery vividness when storytelling description is also presented. This is especially evident in imagery vividness, which confirmed that the animated images enhance imagery vividness only when storytelling description is also present.

\subsection{Willingness-to-pay price premium (WTP)}

Partial least squares (PLS) was used to examine the structural modeling regarding the effects of experiential values and imagery vividness on WTP. First of all, the measurement model was assessed. As outlined in Table 5, the measurement items loaded heavily on their respective constructs (i.e., loadings above 0.70), demonstrating adequate reliability [43]. Moreover, the composite reliability and Cronbach's alpha scores in Table 6 demonstrate satisfactory internal consistency. The discriminant validity was also confirmed, as the square root of the average variance extracted (AVE) of each latent variable was greater than the correlations between that latent variable and other latent variables [44]. Furthermore, in Table 5, the loadings of indicators on their respective latent variables are greater than that of other indicators, thus further supporting discriminant validity.

After confirming reliability and validity of the measurement model, the structural model was further analyzed to examine the path significance. The results, as illustrated in Figure 4, indicate that both experiential value $(\beta=0.543, p<0.001)$ and imagery vividness $(\beta$ $=0.296, p<0.001)$ had significant positive effects on WTP $\left(R^{2}=60.3 \%\right)$. Hence, $\mathrm{H} 7$ and $\mathrm{H} 8$ were supported.
To further confirm that experience value and imagery vividness indeed mediated the effect of animated images and storytelling descriptions on WTP, a bootstrap test was conducted (with 500 bootstrap samples and 95\% bias-corrected confidence intervals). While the results indicate that the indirect effect of storytelling description on WTP was positive and significant $(95 \% \mathrm{CI}=0.201$ to $0.418 ; p<0.001)$, the indirect effect of animated images on WTP was not significant $(95 \% \mathrm{CI}=-0.151$ to $0.075 ; p>0.5)$. As animated images affected imagery vividness only when storytelling description was also provided, a moderated mediation model was thus tested. Indeed, the bootstrapping test results for the moderated mediation model demonstrates that the animated images had positive and significant indirect effect on WTP only when moderated by storytelling description $(95 \% \mathrm{CI}=$ 0.013 to $0.117 ; p<0.10$ ).

Overall, the results demonstrate that animated images and storytelling description are more effective when presented together in increasing not only experiential value and imagery vividness but also WTP.

Table 5. Loadings and cross loadings of measures

\begin{tabular}{|c|c|c|c|}
\hline & $\begin{array}{c}\text { Experiential } \\
\text { Value }\end{array}$ & $\begin{array}{c}\text { Imagery } \\
\text { Vividness }\end{array}$ & WTP \\
\hline EV1 & $\mathbf{0 . 8 9 9}$ & 0.546 & 0.639 \\
\hline EV2 & $\mathbf{0 . 8 0 2}$ & 0.577 & 0.596 \\
\hline EV4 & $\mathbf{0 . 8 5 1}$ & 0.605 & 0.576 \\
\hline EV5 & $\mathbf{0 . 8 8 4}$ & 0.645 & 0.691 \\
\hline IV1 & 0.516 & $\mathbf{0 . 8 9 3}$ & 0.545 \\
\hline IV2 & 0.62 & $\mathbf{0 . 9 2 7}$ & 0.604 \\
\hline IV3 & 0.707 & $\mathbf{0 . 9 1 7}$ & 0.708 \\
\hline IV4 & 0.655 & $\mathbf{0 . 8 2 6}$ & 0.558 \\
\hline IV5 & 0.546 & $\mathbf{0 . 8 9 7}$ & 0.544 \\
\hline WTP1 & 0.723 & 0.68 & $\mathbf{0 . 9 5 4}$ \\
\hline WTP2 & 0.726 & 0.626 & $\mathbf{0 . 9 6 9}$ \\
\hline WTP3 & 0.719 & 0.638 & $\mathbf{0 . 9 8 1}$ \\
\hline
\end{tabular}




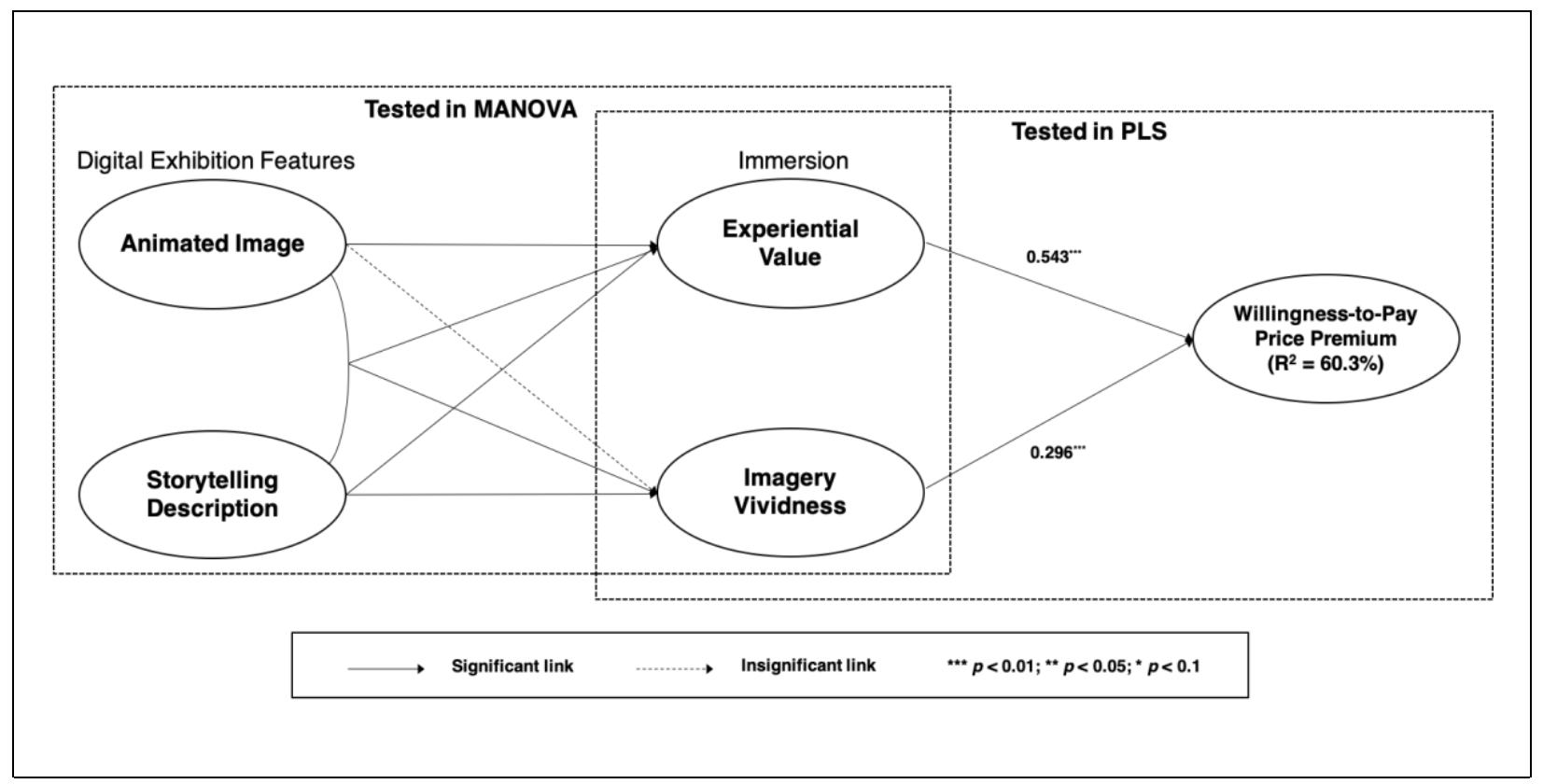

Figure 4. Research framework: testing results

Table 6. Internal consistency and discriminant validity of constructs

\begin{tabular}{|l|c|c|c|c|c|}
\hline & $\begin{array}{c}\text { Composite } \\
\text { reliability }\end{array}$ & $\begin{array}{c}\text { Cronbach's } \\
\text { alpha }\end{array}$ & $\begin{array}{c}\text { Experiential } \\
\text { value }\end{array}$ & $\begin{array}{c}\text { Imagery } \\
\text { vividness }\end{array}$ & WTP \\
\hline $\begin{array}{l}\text { Experiential } \\
\text { value }\end{array}$ & 0.939 & 0.918 & 0.869 & 0.893 & \\
\hline $\begin{array}{l}\text { Imagery } \\
\text { vividness }\end{array}$ & 0.951 & 0,936 & 0.688 & 0.670 & 0.968 \\
\hline WTP & 0.978 & 0.966 & 0.746 & \\
\hline
\end{tabular}

${ }^{* \star}$ Bold numbers are the square roots of the AVE values, while the off-diagonal elements are correlations between the variables.

\section{Discussions and implications}

In this paper, we not only examined the main and interaction effect of digital exhibition features but also confirmed the mediating effects of the experiential value and imagery vividness on WTP. First of all, the individual effect of digital exhibition features on two elements of immersive experience were measured; The results confirmed that, except for the effect of animated images on imagery vividness, the effects of individual digital exhibition features on immersion was positive and significant. One of the possible explanations to the rejection of our hypothesis on the effect of animated images on imagery vividness could be the difference in display size between the actual digital exhibitions and the experiment. Nevertheless, our MANOVA analysis revealed that, while animated images alone did not have significant impact on imagery vividness, it did have significant and positive effect when presented with storytelling description. Lastly, the structural model of experiential value and imagery vividness on WTP was measured using PLS; The results confirmed the significant and positive effect of both experiential value and imagery vividness on WTP.

This paper provides several academic and practical implications. First, the effect of immersive technologies on users' purchase intentions was examined in a novel context of museum industries. While museums have transformed into tourism sites and started to adopt diverse digital technologies to 
attract more visitors, IS researches on such technologies remain scant. By examining how specific features of immersive technologies enhance visitors' immersive experiences and purchase intentions, this paper contributes to the IS literature by expanding its research area to a broader interdisciplinary field.

Furthermore, whereas previous studies have only focused on digital exhibition as a whole, this paper examines specific features (animated images and storytelling description), both individually and interactively. By demonstrating that the use of multiple digital exhibition features could further enhance visitors' experiential value and imagery vividness, this paper provides in-depth understandings of the impact of immersive technologies.

In terms of practical implication, this paper provides museum practitioners the insights regarding how digital exhibition technologies could improve traditional exhibitions and lead to more engaging experiences. By focusing on willingness-to-pay price premium, this paper helps museum practitioners in making decisions to transform their traditional exhibitions into a digital format. Lastly, as digital exhibition is highly feasible throughout diverse media, such as website or social media, the results of this paper could be applicable to diverse contexts within museum industries.

\section{Limitations and suggestions for future research}

Although this paper provides novel and comprehensive understandings of digital exhibitions on visitor's immersive experience and WTP, it is not without limitations. First, while major art museum visitors' age ranges from twenties to forties, the participants of our experiment were undergraduate students in their twenties. Nevertheless, as digital exhibitions are mostly embraced by younger generations, we believe that the age of our participants does not a serious issue. ${ }^{1}$ In the future research, however, it would be better to include diverse age groups. Second, the subjects were exposed to different forms of artworks and descriptions for only limited period of time, which may have been difficult for them to experience the full immersion. Thus, in the future research, providing longer time to experience an artwork is recommended. Third, participants' previous knowledge about Vincent van Gogh's life would have influenced the results. Although we have not measured participants' knowledge about the artist in this experiment, we expect that it would have positively affected immersive experience and WTP because

\footnotetext{
${ }^{1}$ https://www.businessinsider.com/how-5-key-art-industry-insidersare-handling-coronavirus-pandemic-2020-5
}

digital exhibitions create additional values (i.e., experiential and imagery vividness). Lastly, as art museums are currently incorporating even more novel technologies, such as VR and AR, into their exhibitions, studying the immersive effects of these technologies would provide further theoretical and managerial insights.

\section{Conclusion}

Despite the active attempts of art museums to become attractive tourism sites with diverse exhibition technologies, significant IS research progress on the impact of digital exhibitions is yet to be made. As such, this paper provides a comprehensive understanding of digital exhibition, a relatively new exhibition style, by examining the impact of its specific features on visitors' immersive experience as well as willingness-to-pay price premium. The results advocate for the usage of multiple features to enhance not only visitors' immersive experiences but also their willingness-to-pay price premium. These findings serve as a basis for future development in both IS literature and yield valuable insights for museum industry practitioners.

\section{References}

[1] A. Stephen, "The Contemporary Museum and Leisure: Recreation as a Museum Function", Museum Management and Curatorship (19:3), 2007, pp. 297308.

[2] S. Rodney, "How Museum Visitors Became Consumers", Culturecom, 2015.

[3] J. Pallud, and E. Monod, "User Experience of Museum Technologies: The Phenomenological Scales", European Journal of Information Systems (19:5), 2017, pp. 562-580.

[4] Y. Tim, S.L. Pan, and T.H. Ouyang, "Museum in the Age of Digital Transformation", PACIS, 2018, p. 102.

[5] A. Sansom, "Paris digital art venue Atelier des Lumières is a hit, and expanding abroad" The Art Newspaper, 2019.

[6] M.R. Oh, "Jeju Bunker de Lumieres exceeded 100,000 visitors", News1, 2020.

[7] N. Kotler, and P. Kotler, "Can Museums Be All Things to All People? Missions, Goals, and Marketing's Role", Museum Management and Curatorship (18:3), 2000, pp. 271-287.

[8] M.L. Anderson, "Museums of the Future: The Impact of Technology on Museum Practices", Daedalus (128:3), 1999, pp. 129-162.

[9] G. McPherson, "Public memories and private tastes: The shifting definitions of museums and their visitors in the UK", Museum Management and Curatorship (21:1), 2006, pp. 44-57.

[10] B.L. Rottenberg, "Museums, Information and the Public Sphere", Museum International (54:4), 2002, pp. 
21-28.

[11] T. Weng, "The 19th century official paris salon exhibition digital museum", WSEAS Transactions on Information Science and Applications (12:6), 2009, pp. 1903-1912.

[12] S.Y. Hung, C.C. Chen, H.M. Hung, and W.W. Ho, "Critical factors predicting the acceptance of digital museums: User and system perspectives", Journal of Electronic Commerce Research (14:3), 2013, pp.231.

[13] T.H. Jung, and M.C. Dieck, “Augmented reality, virtual reality and $3 \mathrm{D}$ printing for the co-creation of value for the visitor experience at cultural heritage places", Journal of Place Management and Development, 2017.

[14] I. Elgammal, M. Ferretti, M. Risitano, and A. Sorrentino, "Does digital technology improve the visitor experience? A comparative study in the museum context", International Journal of Tourism Policy (10:1), 2020, pp. 47-67.

[15] IBISWorld, "Museum Industry in the Us - Market Research Report," 2019.

[16] Digital Exhibition, "Definition", from https://www.digitalexhibitions.org/?lan=en\&q=Referen ces/Definition.

[17] Culture Station Seoul 284, "Van Gogh Inside", from https://www.seoul284.org/.

[18] B.G. Witmer, and M.J. Singer, "Measuring presence in virtual environments: A presence questionnaire", Presence (7:3), 1998, pp. 225-240.

[19] R. Agarwal and E. Karahanna, "Time flies when you're having fun: Cognitive absorption and beliefs about information technology usage", MIS quarterly, 2000, pp. 665-694.

[20] C. Dede, "Immersive interfaces for engagement and learning" Science (323:5910), 2009, pp. 66-69.

[21] Murray, J.H, Hamlet on the Holodeck: The Future of Narrative in Cyberspace, Free Press, New York, 1997.

[22] C.T. Vi, D. Ablart, E. Gatti, C. Velasco, and M. Obrist, "Not Just Seeing, but Also Feeling Art: Mid-Air Haptic Experiences Integrated in a Multisensory Art Exhibition", International Journal of Human-Computer Studies (108), 2017, pp. 1-14.

[23] Z. He, L. Wu, and X. Li, "When Art Meets Tech: The Role of Augmented Reality in Enhancing Museum Experiences and Purchase Intentions", Tourism Management (68), 2018, pp. 127-139.

[24] M.B. Holbrook, and R.M. Schindler, "Age, Sex, and Attitude toward the Past as Predictors of Consumers' Aesthetic Tastes for Cultural Products," Journal of Marketing Research (31:3), 1994, pp. 412-422.

[25] V.A. Zeithaml, "Consumer Perception of Price, Quality, and Value: A Means-End Model and Synthesis of Evidence," Journal of Marketing (52:3), 1988, pp. 2-22.

[26] P.F. Bone, and P.S. Ellen, "The generation and consequences of communication-evoked imagery", Journal of Consumer Research (19:1), 1992, pp. 93-104.

[27] Starr, G. G. Feeling beauty: The neuroscience of aesthetic experience, Mit Press, 2013.

[28] A.M. Belfi, E.A. Vessel, and G.G. Starr, "Individual Ratings of Vividness Predict Aesthetic Appeal in Poetry", Psychology of Aesthetics, Creativity, and the
Arts (12:3), 2018, pp. 341-350.

[29] A. Manthiou, S. Lee, L. Tang, and L. Chiang, "The Experience Economy Approach to Festival Marketing: Vivid Memory and Attendee Loyalty", Journal of Services Marketing (28:1), 2014, pp. 22-35.

[30] V.M. Weng, "From 'Stillness Becoming'to 'Making Time'Digital Surface within My New Media-Art Practice", Procedia-Social and Behavioral Sciences (122), 2014, pp. 82-91.

[31] S. Cubitt, "Visual and Audiovisual: From Image to Moving Image", journal of Visual Culture (1:3), 2002, pp. 359-368.

[32] Boris, V. What Makes Storytelling So Effective for Learning. Harvard Business Publishing, 2017.

[33] C.B. Rose, and C.A. Granger, "Unexpected selfexpression and the limits of narrative inquiry: Exploring unconscious dynamics in a community-based digital storytelling workshop", International Journal of Qualitative Studies in Education (26:2), 2013, pp. 216237.

[34] L. Terrenghi, and A. Zimmermann, "Tailored Audio Augmented Environments for Museums", Proceedings of the 9th International Conference on Intelligent User Interfaces, 2004, pp. 334-336.

[35] B. Klein, and K.B. Leffler, "The role of market forces in assuring contractual performance", Journal of political Economy (89:4), 1981, pp. 615-641.

[36] J.J. Clarkson, C. Janiszewski, and M.D. Cinelli, "The desire for consumption knowledge. Journal of Consumer Research (39:6), 2013, pp. 1313-1329.

[37] L. Nicolao, J.R. Irwin, and J.K. Goodman, "Happiness for sale: Do experiential purchases make consumers happier than material purchases?", Journal of consumer research (36:2), 2009, pp.188-198.

[38] L. Mackiewicz, and F. Melendez, "Loving vincent: guiding painters through 64.000 frames", ACM SIGGRAPH 2016 Talks, 2016, pp. 1-2.

[39] C. Mathwick, N. Malhotra, and E. Rigdon, “ Experiential value: conceptualization, measurement and application in the catalog and Internet shopping environment", Journal of retailing (77:1), 2001, pp. 3956.

[40] D.A. Baker, and J.L. Crompton, "Quality, satisfaction and behavioral intentions", Annals of tourism research (27:3), 2000, pp. 785-804.

[41] A. Dwivedi, T. Nayeem, and F. Murshed, "Brand experience and consumers' willingness-to-pay (WTP) a price premium: Mediating role of brand credibility and perceived uniqueness", Journal of Retailing and Consumer Services (44), 2018, pp. 100-107.

[42] C. Yi, Z. Jiang, and I. Benbasat, "Designing for diagnosticity and serendipity: An investigation of social product-search mechanisms", Information Systems Research (28:2), 2017, pp. 413-429.

[43] J.F. Hair, W.C. Black, B.J. Babin, R.E. Anderson, R.L. Tatham. Multivariate data analysis. Upper Saddle River, NJ. Prentice hall, 1998.

[44] D. Barclay, R. Thompson, and C. Higgins "The partial least squares (PLS) approach to causal modeling: Personal computer adoption and use as an illustration", Tech. Stud. (2:2), 1995, pp. 285-309. 